\title{
CARACTERÍSTICAS HIDROLÓGICAS DO SOLO SATURADO NA RESERVA FLORESTAL ADOLPHO DUCKE - AMAZÔNIA CENTRAL ${ }^{1}$
}

\author{
Juan Daniel Villacis Fajardo ${ }^{2}$, Savio Jose Filgueira Ferreira ${ }^{3}$, Sebastião Átila Fonseca Miranda ${ }^{3}$ e Ari \\ de Oliveira Marques Fillho ${ }^{3}$
}

\begin{abstract}
RESUMO - Neste estudo, investigaram-se a porosidade e condutividade hidráulica da zona saturada do solo, buscando entender como essas variáveis físicas afetam os processos hidrológicos em uma área de floresta primária, sob pressão urbana, na Amazônia central. O experimento foi realizado na Reserva Florestal Adolpho Ducke, localizada ao norte da cidade de Manaus, AM. No igarapé Bolívia foi instalado um posto fluviométrico (régua linimétrica e linígrafo); no local, foram instalados quatro piezômetros na zona ripária, perpendicular ao curso do igarapé. A porosidade variou no perfil do solo, alcançando valores acima de $0,40 \mathrm{~cm}^{3} / \mathrm{cm}^{3}$. Os valores médios de condutividade hidráulica saturada ou infiltração básica $(K)$ foram elevados e variaram de 89,5 $\pm 12,8$ a $279,5 \pm 9,0 \mathrm{~mm} / \mathrm{h}$. O nível d'água no igarapé oscilou entre 65 e $141 \mathrm{~cm}$, no período de observação (novembro de 2005 a outubro de 2007). O piezômetro da camada profunda do solo, distante do curso d'água, variou entre 166,2 e 304,9 cm. As condutividades hidráulicas do solo saturado foram maiores nos pontos mais distantes do curso d'água, tanto na camada superficial quanto na profunda, determinando o comportamento hidrológico do lençol freático no local.
\end{abstract}

Palavras-chave: Hidrologia, Porosidade e Condutividade hidráulica do solo e floresta equatorial.

\section{HYDROLOGICAL CHARACTERISTS OF THE SATURED SOIL IN THE ADOLPHO DUCKE FOREST RESERVE - CENTRAL AMAZONIA}

\begin{abstract}
This study investigated the porosity and the hydraulic conductivity on the saturated zone of the soil trying to understand how these physical variables affect the hydrological processes, in an area of primary forest under urban pressure, in Central Amazonia. The experiment was carried out in the Adolpho Ducke Forest Reserve, located on the north of the city of Manaus - AM. One water measurement station (water level scale) was installed in the Igarapé Bolivia and four piezometers were installed in the site, the latter on the riparian zone, perpendicular to the course of the stream. The porosity varied in the soil profile, reaching values above $0.40 \mathrm{~cm}^{3} / \mathrm{cm}^{3}$. The mean values for the saturated hydraulic conductivity or basic infiltration (K) were high and varied from $89.5 \pm 12.8$ to $279.5 \pm 9.0 \mathrm{~mm} / \mathrm{h}$. The stream water level varied from 65 to $141 \mathrm{~cm}$ in the observation period (November of 2005 to October of 2007). The deep soil layer piezometer, away from the water stream, varied from 166.2 e $304.9 \mathrm{~cm}$. The hydraulic conductivities of the saturated soil increase with the distance from the stream on the two studied layers, determining the hydrological behavior of the water table in that site.
\end{abstract}

Keywords: Hydrology, Porosity and Soil hydraulic conductivity and rain forest.

\section{INTRODUÇÃO}

Nas bacias hidrográficas com cobertura de floresta natural, a vegetação promove a proteção contra a erosão dos solos, a sedimentação, a lixiviação excessiva de nutrientes e a elevação da temperatura da água. As áreas de florestas não perturbadas representam a melhor proteção dos recursos hídricos, e o monitoramento hidrológico de microbacias com floresta natural serve como referência para comparação com outras microbacias impactadas, simultaneamente monitoradas (ARCOVAe CICCO, 1999).

\footnotetext{
${ }^{1}$ Recebido em 27.12.2007 e aceito para publicação em 02.03.2010.

${ }^{2}$ Universidade do Estado do Amazonas, UEA, Brasil. E-mail: <davifa28@yahoo.com>.

${ }^{3}$ Instituto Nacional de Pesquisas da Amazônia, INPA,Brasil. E-mail: <savio@inpa.gov.br>, <atila@inpa.gov.br>e <ari@inpa.gov.br>.
} 
A interferência antrópica no meio ambiente e a utilização inadequada das terras vêm gerando a insustentabilidade dos recursos naturais; e o manejo irracional dos solos, muitas vezes, inviabiliza o equilíbrio dos ecossistemas. A fim de minimizar os efeitos causados pelas ações antrópicas, torna-se necessário estabelecer técnicas de conservação do solo, associadas à observação do uso do solo na paisagem e da movimentação da água, em uma situação específica de cada área (SANTOS et al., 2007). Além disso, é necessário antes conhecer as características hidrológicas do ecossistema natural, para depois fazer a comparação com aqueles em que ocorreu intervenção antrópica (CARDOSO et al., 2006).

A Reserva Florestal Ducke possui vários igarapés, entre os quais se destacam: Barro Branco, Acará, Tinga e Bolívia. Nas últimas décadas, a cidade de Manaus vem circundando a reserva, tornando-a exemplo singular em função da forte pressão ocupacional, que tende a transformá-la em uma grande área verde isolada, sob a ação crescente de elementos poluidores. Nas condições atuais, os estudos das relações hídricas (transformação chuva-escoamento, transporte de material em suspensão etc.) e ciclagem de nutrientes constituirão referencial apropriado para o controle e acompanhamento das modificações impostas ao sistema natural no futuro e a outros sistemas hidrológicos da área urbana de Manaus. Desde agosto de 2004, a Coordenação de Pesquisas em Clima e Recursos Hídricos do INPA vem desenvolvendo estudos de hidrologia superficial e subterrânea e sobre a ciclagem de nutrientes, na bacia hidrográfica do Igarapé Bolívia. A Reserva Ducke foi escolhida para esses estudos por proporcionar algumas vantagens, como: canal tecnicamente adequado para as medidas de descargas, diferentes topossequências (platô, encosta (vertente) e baixio) e ponto de medidas relativamente protegido da ação de invasores.

No solo da área deste estudo, a distribuição de partículas e as suas características nas diferentes camadas são as seguintes: 0-10 cm - camada cinza muito escura composta de matéria orgânica e raízes disseminadas; $10-20 \mathrm{~cm}$ - camada cinza-escura, areia variando de fina a média com partículas com diâmetro variando de 0,1 a 0,5 mm; 20-30 cm - camada com areia também variando de fina a média; 30-50 cm - camada com areia variando de fina a grossa com partículas de diâmetro variando de 0,1 a 1,0 mm; e 50 a 100 cm - camada com areia variando de média a grossa e contendo seixos, diâmetros das partículas de areia variando de 0,25 a 2,5 mm. A textura é predominantemente arenosa, com baixa fertilidade química, consequentemente a disponibilidade de nutrientes para as plantas é baixa e o solo pode ser classificado como distrófico, com baixos valores de capacidade de troca catiônica efetiva; a sustentação da floresta provém da ciclagem de nutriente, com contribuição das condições de calor, alta umidade e diversidade biológica (ALMEIDA et al., 2005).

Este estudo objetivou avaliar as características físicas do solo na zona saturada, com a finalidade de contribuir para o entendimento de processos hidrológicos em área de floresta primária, próxima ao curso d’água (baixio), na bacia hidrográfica do igarapé Bolívia, visando estabelecer um referencial de comportamento para outros ambientes hídricos da região central da Amazônia.

\section{MATERIAL E MÉTODOS}

O sistema de medidas hidrológicas foi instalado em agosto de 2004, na bacia hidrográfica do igarapé Bolívia, localizada ao sul da Reserva Florestal Adolpho Ducke (Figura 1), com área de 100 km² (10 x 10 km), na periferia de Manaus, e latitude de $02^{\circ}$ 53' S e longitude de $59^{\circ} 58^{\prime} \mathrm{W}$.

\subsection{Porosidade do solo}

O volume total de poros foi determinado com uma sonda de nêutrons (Modelo IH, Didcot Instrument Co, Abingdon, Inglaterra), que é utilizada para medir a umidade do solo. Em condições de solo saturado, todo o espaço

(fonte: INPE/2004).

(Source: INPE/2004).

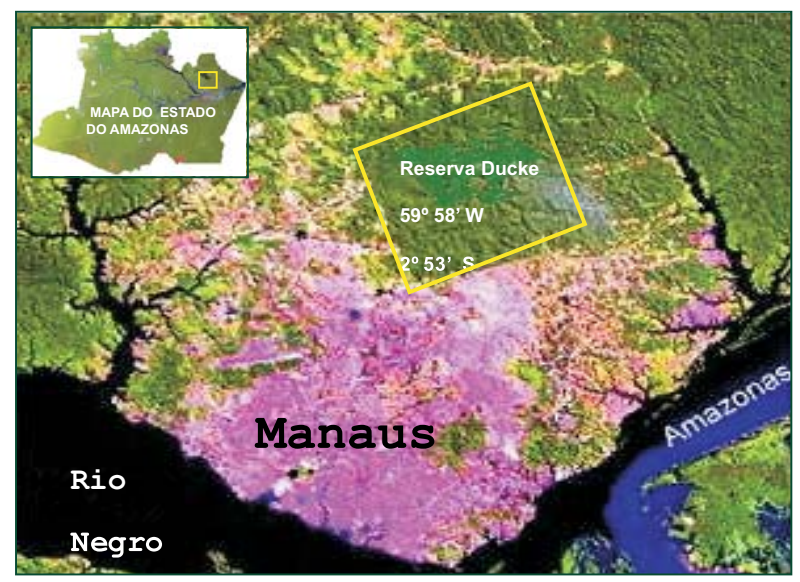

Figura 1 - Imagem de satélite mostrando os limites da Reserva Florestal Adolpho Ducke.

Figure 1 - Satellite image showing limits of Adolpho Ducke Reserve. 
de vazios é ocupado pela água. A umidade saturada corresponde às leituras efetuadas abaixo do nível do lençol freático. Para a realização das medidas foi instalado um tubo de acesso de alumínio, e as leituras foram feitas nas seguintes profundidades: 20, 40, 60, 80, 100, 120,140 e $160 \mathrm{~cm}$.

\subsection{Condutividade hidráulica na zona saturada $\left(K_{0}\right)$}

A condutividade hidráulica foi determinada utilizando-se o método de Hvorslev, Fetter (1988), que consiste em criar uma diferença de potencial hidráulico entre o interior de um piezômetro e suas vizinhanças, no aquífero onde ele está parcialmente inserido. Essa diferença de potencial é gerada por elevação ou rebaixamento do nível d’água no piezômetro a partir do nível estático; depois disso, registra-se em intervalos de tempo determinados o nível da água à medida que este desce ou sobe, para recuperar novamente o nível estático inicial.

O procedimento adotado neste trabalho consistiu em esvaziar o tubo até certo nível, associando esse nível ao tempo inicial $(\mathrm{t}=0)$; a partir daí, as variações do nível d’água com o tempo são registradas. Essa recuperação de nível implica fluxo de água para dentro do piezômetro, ocasionado pelo potencial hidráulico

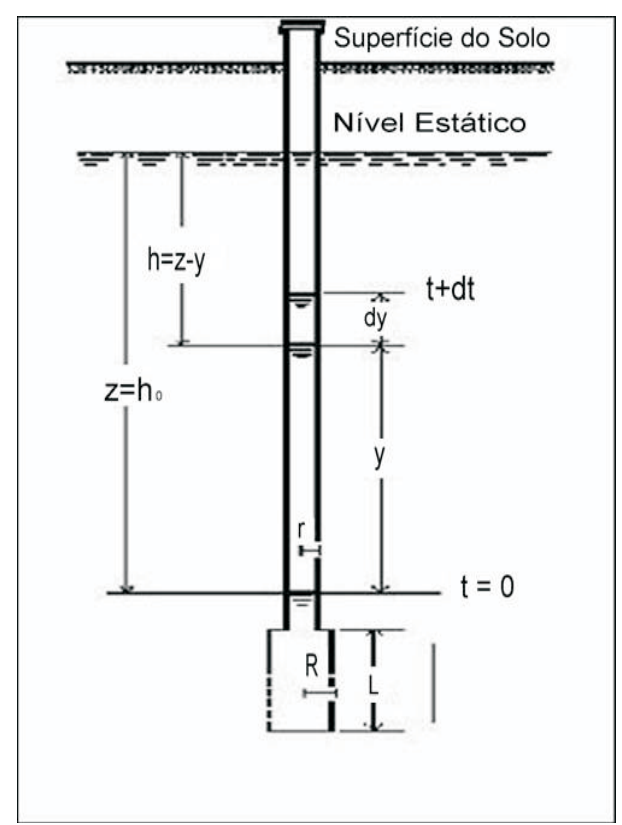

Figura 2 - Esquema de funcionamento do piezômetro. Figure 2 - Schematic of operation of the piezometer. decorrente do processo de esvaziamento. A taxa de entrada do volume d'água $\boldsymbol{q}$, no piezômetro, em qualquer tempo $\boldsymbol{t}$, é proporcional à condutividade hidráulica do solo $\boldsymbol{K}$, à diferença entre o nível estático e o nível d'água no tempo $\mathrm{t}(\mathrm{h}=\mathrm{z}-\mathrm{y})$ e a um fator de forma $\mathrm{F}$, associado à geometria do piezômetro (Figura 2).

Essa taxa q de entrada d'água no intervalo de tempo dt, num piezômetro com seção transversal A, é dada pela equação 1 .

$\mathrm{q}=\mathrm{F} \cdot \mathrm{K} \cdot(\mathrm{z}-\mathrm{y})=\frac{\text { Volume } d^{\prime} \text { água }}{d t}=\frac{A \cdot d y}{d t}$

Essa equação diferencial de primeira ordem pode ser simplificada com a substituição de variáveis $\mathrm{h}=\mathrm{z}-\mathrm{y}, \mathrm{dh}=$-dy; e com a definição do tempo T, que Hvorslev chamou de tempo de retardo básico, como o tempo necessário para igualar a diferença de pressão (retornar ao nível estático, se fosse mantida a taxa de fluxo inicial $q_{0}$, ou:

$\mathrm{T}=\frac{\text { Volume inicial }}{q_{0}}=\frac{A \cdot h_{0}}{F \cdot K \cdot h_{0}}=\frac{A}{F \cdot K}$

A equação diferencial simplificada assume a seguinte forma:

$\frac{d h}{d t}=-\frac{h}{T}$

cuja solução, sob a condição-limite $\mathrm{t}=0, \mathrm{~h}=\mathrm{h}_{0}$, tem a fórmula:

$h=h_{0} \cdot e^{-\frac{t}{T}}$

Para determinar o valor de $\mathrm{T}$, plota-se $\mathrm{h} / \mathrm{h}_{0}$ (em escala logarítmica) versus $\mathrm{t}$ (em escala linear); com a equação da reta mais bem ajustada a esses pontos, obtém-se o valor de $\mathrm{T}$, que corresponde a $\mathrm{h} / \mathrm{h}_{0}=\mathrm{e}^{-1} \cong 0,37$ (equação 4, quando $\mathrm{t}=\mathrm{T}$ ).

De acordo com o que foi visto, o valor de $\boldsymbol{K}$ vai depender de um fator $\boldsymbol{F}$, que está relacionado com a forma e as dimensões do piezômetro. Segundo Freeze e Cherry (1979), para piezômetros com $L / R>8$ Hvorslev avaliou o fator de forma $\mathrm{F}$, de modo que:

$\mathrm{K}=\frac{\mathrm{r}^{2} \ln (\mathrm{L} / \mathrm{R})}{2 \mathrm{LT}}$

Revista Árvore, Viçosa-MG, v.34, n.4, p.677-684, 2010 
sendo L a altura da região através da qual a água penetra no piezômetro, r é o raio externo do tubo e $\mathrm{R}$ é o raio que vai do centro do tubo até a parte externa do envelope de cascalho, que é normalmente utilizado para revestir esses equipamentos.

Utilizou-se a equação 5 para determinar os valores das condutividades hidráulicas, uma vez que o sistema de medidas atendeu aos requisitos físicos do método descrito anteriormente.

\subsection{Nível d’água subterrânea e nível d’água do igarapé}

No processo de perfuração do solo para a instalação de piezômetros, percebeu-se mudança nas características físicas do solo a partir de $1 \mathrm{~m}$ de profundidade, deixando evidente a existência de duas camadas bem distintas. A disposição dos piezômetros em duas linhas transversais ao curso d’água foi adotada para caracterização adequada dessas duas camadas: a primeira linha com piezômetros dispostos em profundidades menores (90 cm e 110 cm), distantes 5 e 10 m do curso d'água, respectivamente; as medidas desses aparelhos representaram contribuição isolada da condutividade hidráulica da camada superior do solo; em contrapartida, nos períodos de estiagem esses equipamentos ficam inoperantes (P3 e P4, Figura 3); a segunda linha transversal (distante 7,5 m da anterior) com piezômetros dispostos em profundidades maiores (206 cm e 265 cm), distantes 5 e 10 m do curso d'água, respectivamente; as medidas desses aparelhos representaram a

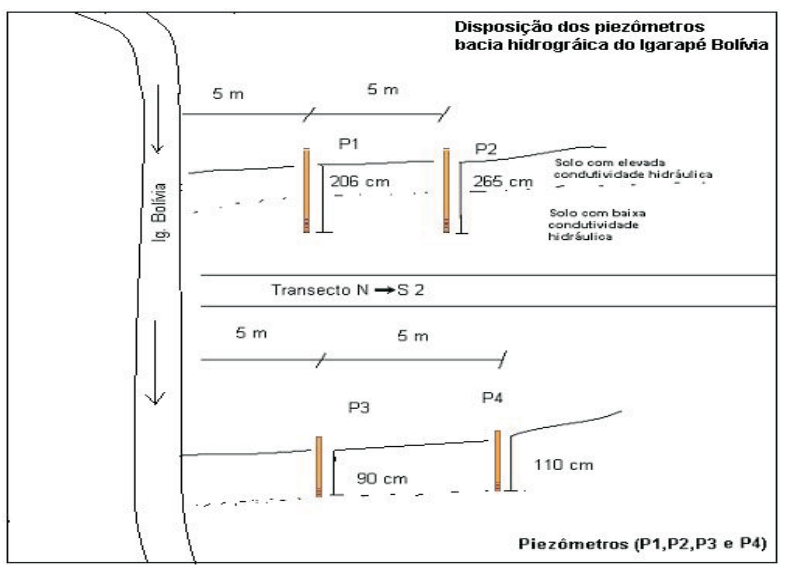

Figura 3 - Disposição dos piezômetros em linhas transversais ao curso d'água.

Figure 3-Arrangement of piezometers in lines across the stream. contribuição isolada da condutividade hidráulica da camada inferior do solo; esses piezômetros mantiveram-se sempre submersos no lençol freático (P1 e P2, Figura 3).

As alturas da superfície do solo onde foram instalados os piezômetros, considerando-se como referência o leito do igarapé, foram:

$\begin{array}{ll}\text { Piezômetro 1 } & 305 \mathrm{~cm} \\ \text { Piezômetro 2 } & 361 \mathrm{~cm} \\ \text { Piezômetro 3 } & 304 \mathrm{~cm} \\ \text { Piezômetro 4 } & 386 \mathrm{~cm}\end{array}$

Os piezômetros instalados consistem de tubos de PVC de 75 mm de diâmetro externo, contendo furos feitos com broca de $7 \mathrm{~mm}$. Esses furos cobrem uma extensão (L) da parte inferior dos tubos, sendo bem distribuídos nas paredes e envolvidos com uma tela de náilon. Nos piezômetros dispostos na camada superior, a extensão (L) é de $35 \mathrm{~cm}$. Já os piezômetros da camada inferior à extensão (L) medem 45 cm (Figura 4). Com um medidor de profundidade, que era introduzido nos piezômetros, foram determinadas as oscilações do lençol freático semanalmente.

Os níveis d’água do igarapé foram medidos em uma régua linimétrica de $3 \mathrm{~m}$ de altura, instalada no leito do igarapé, à margem esquerda, onde foi instalado um linígrafo de pressão acoplado a um sistema de aquisição de dados da marca Campbell.

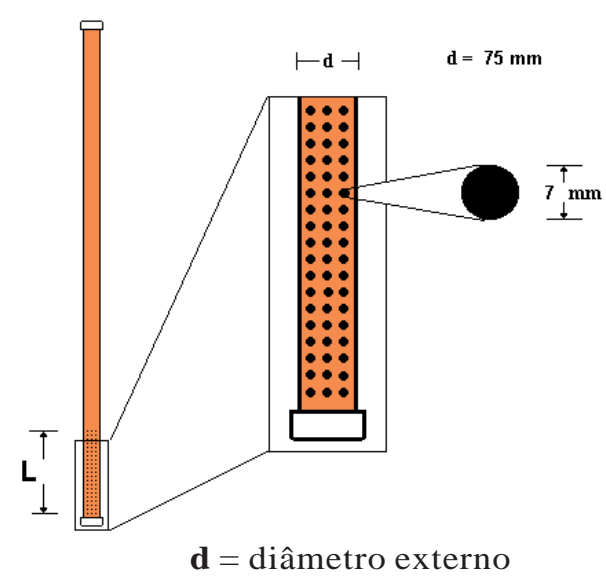

Figura 4 - Esquema dos piezômetros utilizados neste estudo. Figure 4-Diagram of piezometers used in this study. 


\subsection{Análise estatística dos dados}

Os níveis d’água no igarapé foram analisados estatisticamente, comparando-se as médias entre os tratamentos (piezômetros e igarapé). A análise de variância foi feita com o auxílio do software Minitab, utilizando o modelo linear geral (general linear model, GLM). Em seguida, as médias foram comparadas entre si, usando-se o teste de Tukey a 5\%. Para aplicação dos testes, as médias foram agrupadas em dois períodos pluviais distintos: estação chuvosa e estação seca.

\section{RESULTADOS E DISCUSSÃO}

O solo do baixio apresentou estratificação no perfil de porosidade, como mostrado na Figura 5. Para obtenção do perfil de porosidade do solo, utilizaram-se os teores de umidade do solo saturado. Da superfície até a profundidade de $60 \mathrm{~cm}$, os valores referem-se à umidade do solo não saturado e, a partir dessa profundidade, aqueles utilizados são de umidade de solo saturado. Na profundidade de $60 \mathrm{~cm}$, observou-se desvio padrão mais elevado do que nas maiores profundidades, fato que é explicado pela influência da esfera da nuvem de nêutrons, que é função do conteúdo de hidrogênio (conteúdo de água), cujo raio tende a aumentar com a diminuição do teor de água (BACCHI e REICHARDT, 1990). Verificou-se que na profundidade de $60 \mathrm{~cm}$ a porosidade foi mais elevada, ultrapassando o valor de $0,40 \mathrm{~cm}^{3} / \mathrm{cm}^{3}$. Entre as profundidades de 60 e $100 \mathrm{~cm}$, notou-se que os valores de umidade tendiam a diminuir; em seguida, a porosidade aumentou até a profundidade de $120 \mathrm{~cm}$ e, novamente, diminuiu até $160 \mathrm{~cm}$. Possivelmente as frações granulométricas e o arranjo das partículas estivessem provocando essa variabilidade na porosidade do solo.

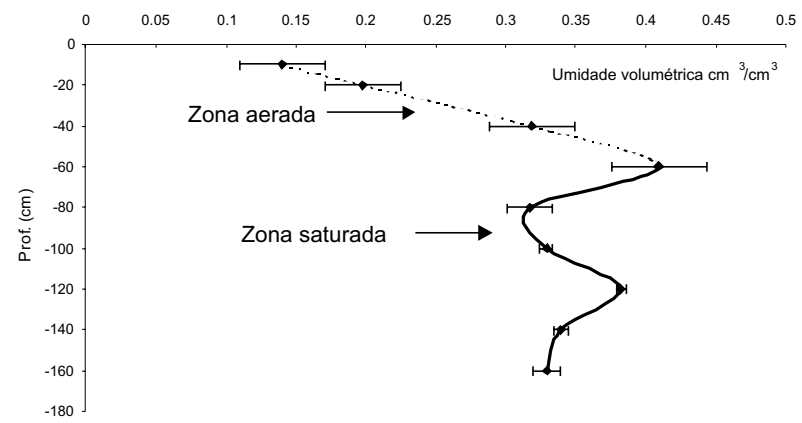

Figura 5 - Distribuição e variação da umidade do solo no perfil em área de baixio.

Figure 5 - Distribution and variation of soil moisture profile in the lowland area.
Os ensaios nos piezômetros, para a determinação da condutividade hidráulica de todos os pontos, foram realizados em triplicata, e na Figura 6 são apresentadas as curvas de h/ho versus o tempo. Nos piezômetros mais profundos, as curvas eram menos inclinadas (Figura 6AB) que as dos piezômetros instalados mais superficialmente (Figura 6CD). Nessas figuras, a diminuição da inclinação indica decréscimo das condutividades hidráulicas do solo.

Na Tabela 1 são mostrados os dados obtidos nas análises de regressão linear: condutividade hidráulica saturada, nível estático calculado (h0 = ea), tempo de retardo $\mathrm{T}$ e coeficientes de determinação $\left(\mathrm{r}^{2}\right)$ para os piezômetros 1, 2, 3 e 4.

Os valores de condutividade hidráulica saturada ou infiltração básica (K) variaram de 78,3 (piezômetro 1) a $287,5 \mathrm{~mm} / \mathrm{h}$ (piezômetro 4). As médias mais baixas foram fornecidas pelas camadas de solo mais profundas, isto é, abaixo de $1 \mathrm{~m}$. Esses resultados são mais elevados do que os obtidos nos seguintes estudos: Ferreira et al. (2002) em Latossolo Amarelo em área de terra firme, na Amazônia central, cujo maior valor foi de $42,7 \mathrm{~mm} / \mathrm{h}$; TOMASELLA e HODNETT (1996) em pastagem formada em 1980 a 100 km de Manaus (Fazenda Dimona), os quais registraram a infiltração na superfície e na profundidade de $105 \mathrm{~cm}$, respectivamente 66 e $17 \mathrm{~mm} / \mathrm{h}$; e Reichardt et al. (1980) em Latossolo Amarelo da Estação Experimental de Silvicultura Tropical do INPA, a cerca de $60 \mathrm{~km}$ de Manaus, com o valor médio 35 mm/h. Tomasella e Hodnett (1996) registraram o valor de 97 mm/h, na camada de 30 cm, na Fazenda Dimona. Esse valor é mais elevado do que o fornecido pelo piezômetro $1(89,5 \mathrm{~mm} / \mathrm{h})$. A condutividade hidráulica saturada acima de $30 \mathrm{~mm} / \mathrm{h}$ é considerada muito alta, de acordo com Reichardt (1990).

Com os dados das oscilações dos níveis d’água dos piezômetros, o valor médio obtido da diferença entre os piezômetros $\mathrm{P} 2$ e $\mathrm{P} 1$ foi de $35,8 \pm 4,5 \mathrm{~cm}$ e entre P4 e P3, 28,7 $\pm 3,4 \mathrm{~cm}$. As diferenças de condutividade hidráulica entre as duas camadas de solo, onde estavam inseridos os piezômetros, explicam as diferenças persistentes entre os gradientes hidráulicas que nelas ocorreram.

A Figura 7 apresenta o comportamento das oscilações dos níveis d'água no igarapé e nos piezômetros 1, 2, 3 e 4, no período de dois anos de medidas semanais. No igarapé, o nível d’água

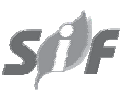

Revista Árvore, Viçosa-MG, v.34, n.4, p.677-684, 2010 
Piezômetro 1

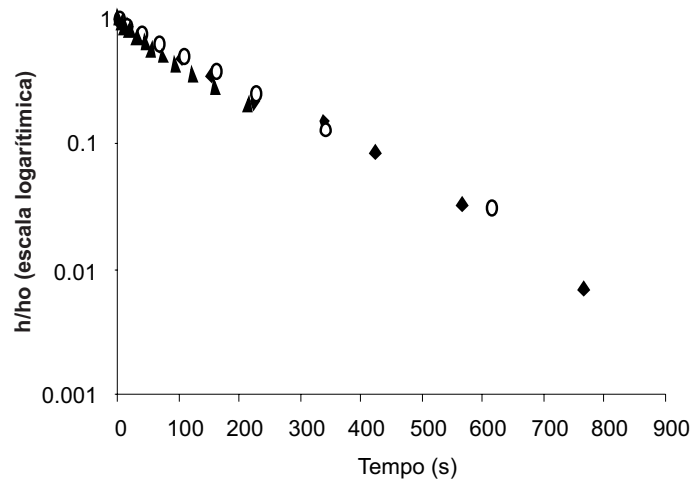

Piezômetro 3

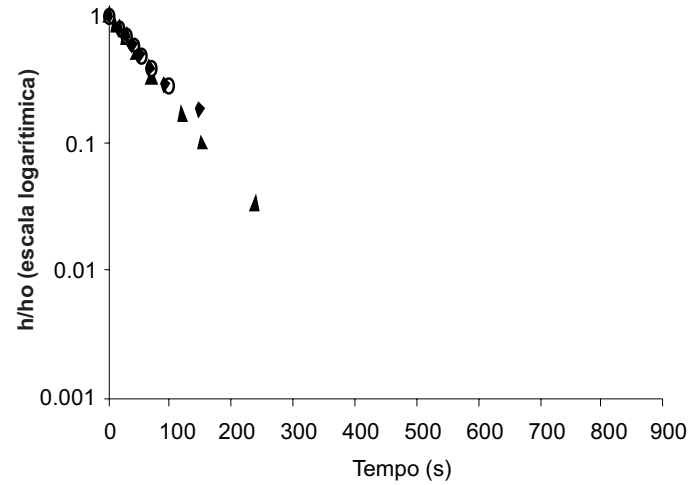

C
A

Piezômetro 2

B
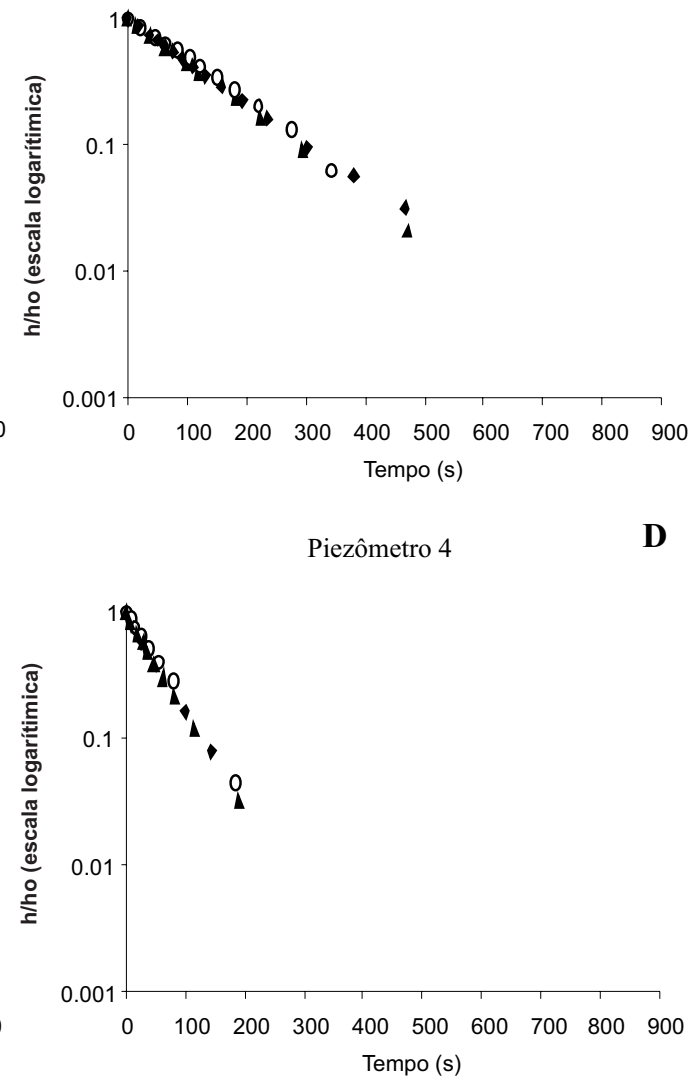

Figura 6 - Curva de h/ho versus o tempo para os piezômetros 1, 2, 3 e 4 .

Figure 6-Curve of h / ho vs. time for piezometers 1, 2, 3 and 4.

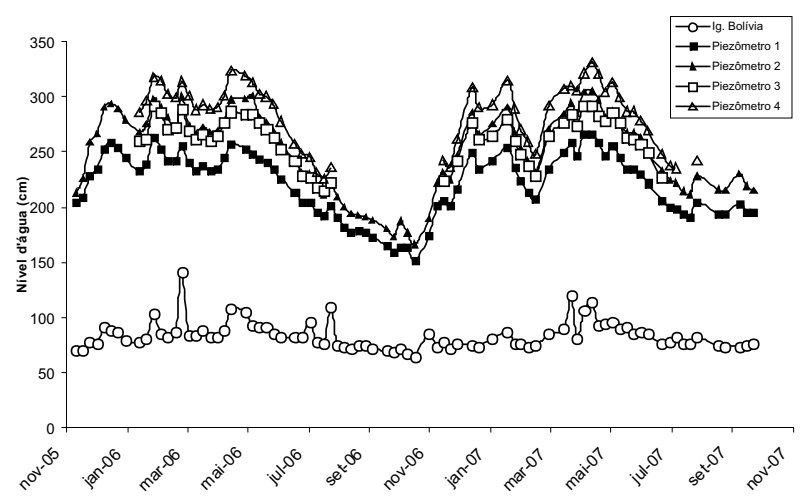

Figura 7-Oscilação do nível d’água do igarapé Bolívia, piezômetro 1, piezômetro 2, piezômetro 3 e piezômetro 4.

Figure 7-Oscillation of the water level of the stream Bolivia, a piezometer, piezometer 2, 3 and piezometer piezometer 4. mais baixo foi de $65 \mathrm{~cm}(25 / 10 / 2006)$ e o mais elevado, de $141 \mathrm{~cm}(08 / 03 / 2006)$. Nos piezômetros 1 e 2 (mais profundos) foi possível registrar a oscilação durante o estudo, mas nos piezômetros 3 e 4 só foi possível registro de janeiro (período chuvoso) a agosto (início da estação seca) de 2006. Observaram-se diferenças significativas dos níveis d’água nos piezômetros, conforme valores mostrados na Tabela 2 .

Os valores observados nos piezômetros mais distantes foram mais elevados em comparação com os valores dos piezômetros colocados próximos à margem do curso d’água, acompanhando a topografia do local; foram também registradas diferenças entre os piezômetros instalados nas mesmas distâncias em relação às margens do igarapé.

Revista Árvore, Viçosa-MG, v.34, n.4, p.677-684, 2010 
Tabela 1 - Condutividade hidráulica saturada (K), nível estático calculado $\mathrm{h}_{0}=\mathrm{e}^{\mathrm{a}}$, tempo de retardo $\mathrm{T}$ e coeficiente de determinação $\mathrm{r}^{2}$ para os piezômetros 1, 2, 3 e 4 .

Table 1 - Saturated hydraulic conductivity $(K)$, calculated static level and ho =, delay time $T$ and coefficient of determination r2 for the piezometers 1, 2, 3 and 4.

\begin{tabular}{|c|c|c|c|c|}
\hline Piezômetro & $\mathrm{K}(\mathrm{mm} / \mathrm{h})$ & $\mathrm{h}_{0}=\mathrm{e}^{\mathrm{a}}(\mathrm{cm})$ & $\mathrm{T}(\mathrm{s})$ & $\mathrm{r}^{2}$ \\
\hline \multirow[t]{3}{*}{1} & 86,7 & 74,0 & 161 & 0,992 \\
\hline & 103,4 & 65,1 & 127 & 0,997 \\
\hline & 78,3 & 75,4 & 179 & 0,999 \\
\hline Média & 89,5 & & & \\
\hline Desvio padrão & 12,8 & & & \\
\hline \multirow[t]{3}{*}{2} & 113,2 & 70,51 & 123 & 1,000 \\
\hline & 107,6 & 73,66 & 130 & 0,993 \\
\hline & 104,8 & 75,08 & 133 & 0,999 \\
\hline Média & 108,6 & & & \\
\hline Desvio padrão & 4,3 & & & \\
\hline \multirow[t]{3}{*}{3} & 232,6 & 28,8 & 69 & 0,998 \\
\hline & 213,2 & 48,8 & 76 & 0,997 \\
\hline & 207,1 & 42,4 & 79 & 0,997 \\
\hline Média & 217,6 & & & \\
\hline Desvio padrão & 13,3 & & & \\
\hline \multirow[t]{3}{*}{4} & 281,1 & 22,8 & 57 & 0,999 \\
\hline & 269,8 & 41,6 & 60 & 0,999 \\
\hline & 287,5 & 52,4 & 56 & 0,999 \\
\hline Média & 279,5 & & & \\
\hline Desvio padrão & 9,0 & & & \\
\hline
\end{tabular}

Tabela 2 - Médias (cm) dos níveis d’água no igarapé Bolívia e nos piezômetros 1, 2, 3 e 4, nas estações seca e chuvosa.

Table 2-Mean (cm) of water levels in the creek and Bolivia in piezometers 1, 2, 3:04, in dry and wet seasons.

\begin{tabular}{lcc}
\hline & Estação seca & Estação chuvosa \\
\hline Igarapé Bolívia & $75,8^{\mathrm{c}}$ & $87,9^{\mathrm{d}}$ \\
Piezômetro 1 & $197,0^{\mathrm{b}}$ & $233,4^{\mathrm{c}}$ \\
Piezômetro 2 & $218,3^{\mathrm{a}}$ & $266,0^{\mathrm{b}}$ \\
Piezômetro 3 & & $262,5^{\mathrm{b}}$ \\
Piezômetro 4 & & $285,7^{\mathrm{a}}$ \\
\hline
\end{tabular}

Médias com mesma letra nas colunas não diferem entre si, al $1 \%$ de probabilidade.

A média do nível d’água no piezômetro 1 foi igual a 233,4 cm e no piezômetro $3,262,5 \mathrm{~cm}$. Os piezômetros 2 e 4 apresentaram as médias 266 e $285,7 \mathrm{~cm}$, respectivamente. Os resultados dos testes estatísticos (Tabelas 2) indicam que essas médias apresentaram diferenças significativas.
No período chuvoso, o nível d’água do igarapé tende a oscilar mais rapidamente do que no período seco, pois a altura do lençol freático no período chuvoso está muito próxima à superfície e, como a camada superficial apresenta condutividade mais elevada, a água chega mais rapidamente ao canal, enquanto no período seco as chuvas, ao infiltrarem no solo, tendem, pela ação da gravidade, a preencher a camada de solo mais profunda, onde a condutividade é mais baixa, proporcionando oscilação menos intensa no nível do igarapé. As diferenças das médias dos níveis d'água entre os períodos seco e chuvoso do igarapé e os piezômetros 1 e 2 foram, respectivamente, 12,$1 ; 36,4$; e 47,7 cm. Verificou-se que apenas os piezômetros 2 e 3 não apresentaram diferenças significativas de suas médias (Tabela 2).

\section{CONCLUSÕES}

A porosidade e condutividade hidráulicas do solo na zona saturada, em área de baixio adjacente ao igarapé Bolívia, foram investigadas neste estudo. A porosidade

Revista Árvore, Viçosa-MG, v.34, n.4, p.677-684, 2010 
do solo, na zona saturada, apresentou oscilações com tendência de redução da porosidade em associação com a profundidade das camadas. Na camada de solo mais superficial, a condutividade hidráulica foi maior do que na camada profunda. No plano horizontal, partindo-se dos pontos mais distantes até a margem do curso d’água, a condutividade hidráulica do solo tendeu a diminuir, acarretando elevação dos níveis d’água do lençol subterrâneo nas proximidades do igarapé. Essas diferenças de condutividade do solo saturado representam os fatores determinantes dos escoamentos superficial e subterrâneo nesse local.

\section{AGRADECIMENTOS}

Somos gratos ao Conselho Nacional de Desenvolvimento Científico e Tecnológico- CNPq, que com os recursos financeiros obtidos dos fundos (CTHIDRO/CNPq-50.3677/03-5 e UNIVERSAL: PROC. No. 472914/2006-5) nos possibilitaram conduzir este estudo.

\section{REFERÊNCIAS}

ALMEIDA, A. A.; FERREIRA, S. J. F.; SILVA, M. S. Dinâmica de nutrientes no solo e sedimento em reserva florestal sob crescente pressão antrópica em seu entorno. In: JORNADA DE INICIAÇÃO CIENTÍFICA DO PIBIC/CNPq/FAPEAM/INPA, 14., 2005, Manaus. Anais... Manaus: 2005.

ARCOVA, F. C. S.; CICCO, V. Qualidade da água de microbacias com diferentes usos do solo na região de Cunha, São Paulo. Scientia Forestalis, n.56, p.125-134. 1999.
BACCHI, O. O. S.; REICHARDT, K. A sonda de nêutrons e seu uso na pesquisa agronômica. Piracicaba, CENA/USP, 1990. 84p (Boletim Didático)

CARDOSO, C. A. et al. Caracterização hidroambiental da bacia hidrográfica do rio Debossan, Nova Friburgo, RJ. Revista Árvore, v.30, n.2, p.249-256, 2006.

FERREIRA, S. J. F. et al. Propriedades físicas do solo após extração seletiva de madeira na Amazônia central. Acta Amazonica, v.32, n.3, p.449-466, 2002.

FETTER, C. W. Applied hydrogeology. 2.ed. Wisconsin: University of Wisconsin, 1988. 592p.

FREEZE. R. A.; CHERRY, J. A. Groundwater. New York: Prentice-Hall, 1979. 604p.

HILLEL, D. Environmental soil physics. San Diego, Academic Press, 1998. 771p.

REICHARDT, K. et al. Aspectos hídricos de alguns solos da Amazônia - Região do baixo rio Negro. Acta Amazonica, v.10, n.1, p.43-46, 1980.

REICHARDT, K. A água em sistemas agrícolas. São Paulo: Manole. 188p. 1990.

SANTOS, G. V. et al. Análise hidrológica socioambiental da bacia hidrográfica do Córrego Romão dos Reis, Viçosa, MG. Revista Árvore, v.31, n.5, p.931-940, 2007. 